\title{
Ciprofloxacin removal by electro-activated persulfate in aqueous solution using iron electrodes
}

\author{
Mohammad Malakootian ${ }^{1,2} \cdot$ Mohammad Ahmadian $^{2}$ (I)
}

Received: 7 May 2019 / Accepted: 2 July 2019 / Published online: 8 July 2019

(c) The Author(s) 2019

\begin{abstract}
The purpose of this study was to determine the removal efficiency of ciprofloxacin (CIP) by the combined electrochemical-persulfate (EC-PS) process using iron electrodes. The effects of contact time, initial CIP concentration, persulfate (PS) concentration, $\mathrm{pH}$ and current density in CIP removal were investigated. To measure the CIP removal mechanisms in the EC-PS process, radical scavenger analysis, EDS and FTIR were performed on the EC-PS process and produced sludge, respectively. Based on the results obtained, the EC process after 160 min can remove $38 \%$ of CIP, while the PS process had no effect on CIP removal. In contrast, the EC-PS process under the optimum conditions: current density of $1.45 \mathrm{~mA} / \mathrm{cm}^{2}$, PS concentration of $0.42 \mathrm{mM}, \mathrm{pH}$ of 5 , CIP of $10 \mathrm{mg} / \mathrm{L}$ and contact time of $75 \mathrm{~min}$, could reduce the antibiotic by more than $94 \%$. Based on radical scavenger results, radical hydroxyl radicals play a major role in the EC-PS process. Also, by analyzing the results of radical scavenger, FTIR and EDS, it is suggested that the oxidation process was probably dominant in the early stages of the EC-PS process, and then, the electrocoagulation process played a basic role in CIP removal. The results of this study showed that the EC-PS process with a very good efficiency can be used to remove CIP antibiotics from aqueous solutions.
\end{abstract}

Keywords Ciprofloxacin · Electro-persulfate $\cdot$ Aqueous solution · Iron electrodes

\section{Introduction}

The use of drugs, especially antibiotics, has increased dramatically owing to the prevalence and spread of various diseases and the subsequent development of pharmaceutical industries. These drugs are used in various categories in the market for the treatment of various diseases. Fluoroquinolones are one of the largest groups of antibiotics, and, in turn, effluents discharged from pharmaceutical factories and hospital usually contain high concentrations of these compounds. It should be noted that conventional wastewater

Mohammad Ahmadian

moh.ahmadian@yahoo.com

Mohammad Malakootian m.malakootian@yahoo.com

1 Environmental Health Engineering Research Center, Kerman University of Medical Sciences, Kerman, Iran

2 Department of Environmental Health, School of Public Health, Kerman University of Medical Sciences, Medical University Campus, Haft-Bagh Highway, Kerman 7616913555, Iran treatment processes are not able to remove this type of pollutants. Also, the incomplete metabolism of antibiotics in the human and animal bodies and the inadequate disposal of expired antibiotics increase the concentration of these pollutants in wastewater (Ji et al. 2014; Movasaghi et al. 2019; Xiaodong et al. 2017). Ciprofloxacin (CIP) is an antibacterial agent and is a second-generation fluoroquinolone, which is widely used in human and veterinary medicine. It is also responsible for the destruction of both gram-negative and gram-positive bacteria through DNA inhibition (Duan et al. 2018; Tran et al. 2019; Xiaodong et al. 2017). Most antibiotics, such as CIP, are recalcitrant and resistant to biodegradation and releasing them into the environment can cause many adverse ecological effects including cereal reproduction interactions, food destruction and nitrification process disruption and so on. It is also toxic to algae and enhances the growth of antibiotic-resistant bacteria (Flaherty and Dodson 2005; Matzek and Carter 2017; Wu et al. 2013). Different methods have been used to treat wastewaters containing antibiotics. However, due to the process complexity and low biodegradability, conventional biological and physical processes are less efficient. Therefore, researchers have 
recently tested new methods for antibiotic removal from aqueous solutions. Advanced oxidation processes (AOPs) are one of the most important techniques in which highly potent oxidizing agents such as hydroxyl and sulfate radicals are mainly generated. The produced agents can completely degrade a wide range of organic pollutants from industrial wastewater (Lei et al. 2015; Xiaodong et al. 2017). Today, the most AOPs are hydroxyl radical $(\cdot \mathrm{OH})$-base methods, which can quickly and non-selectively remove different organic compounds; therefore, their application is limited due to instability. Recently, another type of AOPs has been developed that is based on radical sulfate $\left(\mathrm{SO}_{4}^{--}\right)$with a halflife longer than $\mathrm{OH}$ (Lei et al. 2015; Matzek and Carter 2016). Sodium persulfate $\left(\mathrm{Na}_{2} \mathrm{~S}_{2} \mathrm{O}_{8}\right)$ is a potent oxidizing agent commonly used in sulfate radical-based AOPs, with some prominent advantages like high stability at room temperature, relatively low cost and less hazardous products (Liu et al. 2018; Romero et al. 2010). The main way to produce $\mathrm{SO}_{4}^{--}$radicals is to activate persulfate with different methods including heat, light, UV, metal ions, microwave and natural mineral materials (Matzek and Carter 2016). Recently, the electrochemical process has been used for persulfate activation in several studies because of its benefits in producing less sludge, thereby reducing both reactor volume and investment costs (Matzek and Carter 2016, 2017). In the electro-persulfate process, the sulfate radical is generated according to Eq. (1). In addition, the persulfate can be regenerated in the anode according to Eq. (2).

$\mathrm{S}_{2} \mathrm{O}_{8}^{2-}+\mathrm{e}^{-} \rightarrow \mathrm{SO}_{4}^{2-}+\mathrm{SO}_{4}^{-}$

$2 \mathrm{SO}_{4}^{2-} \rightarrow \mathrm{S}_{2} \mathrm{O}_{8}^{2-}+2 \mathrm{e}^{-}$

Equation 1 occurs in the cathode and is called the cathodic activation, which leads to the creation of a continuous source of sulfate radicals. Therefore, the combination of electrochemical method and active persulfate can result in continuous production of strong oxidants including $\mathrm{S}_{2} \mathrm{O}_{8}^{2-}$ and $\mathrm{SO}_{4}^{--}$, and, consequently, the decomposition of the contaminants becomes faster and more efficiently (Chen et al. 2014; Lin et al. 2013; Matzek and Carter 2016, 2017). Hence, the aim of this study was to remove CIP from aqueous solutions using the electro-persulfate process.

\section{Materials and method}

\section{Materials}

All chemicals were of analytical grade and purchased from the Merck (Germany). The CIP antibiotic (purity $\geq 98 \%$ ) was obtained from an Iranian pharmaceutical company. Various concentrations of the antibiotic and other chemical
Table 1 Chemical properties of CIP

\begin{tabular}{ll}
\hline Product name & Ciprofloxacin \\
\hline Chemical formula & $\mathrm{C}_{17} \mathrm{H}_{18} \mathrm{FN}_{3} \mathrm{O}_{3}$ \\
Molecular weight & $331.347 \mathrm{~g} / \mathrm{mol}$ \\
Solubility & $25 \mathrm{mg} / \mathrm{mL}$ in $0.1 \mathrm{~N} \mathrm{HCl}$ \\
Chemical structure &
\end{tabular}

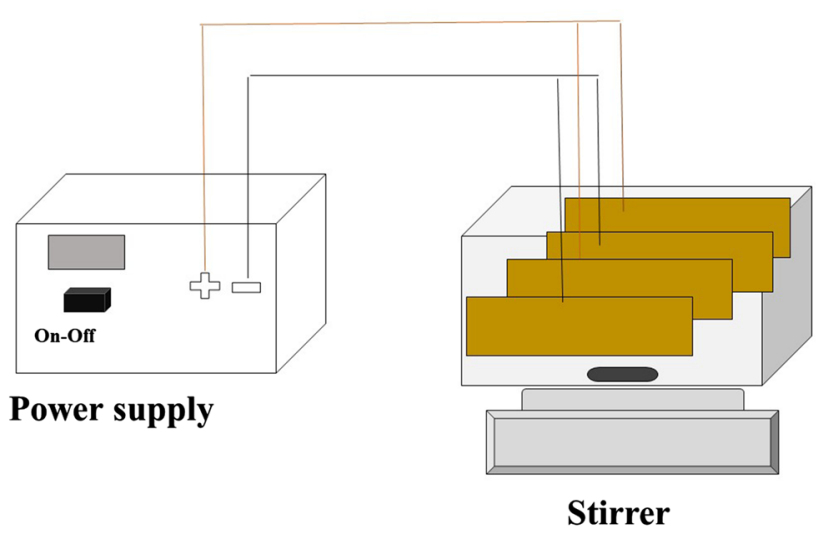

Fig. 1 A schematic diagram of the experimental setup

solutions were prepared with deionized water. The chemical properties of the antibiotic are shown in Table 1.

\section{Pilot characteristics}

Figure 1 shows the pilot used in this study. The $800-\mathrm{mL}$ reactor contained $600 \mathrm{~mL}$ the CIP solution. Inside the reactor, four iron electrodes were used with dimensions of $30 \mathrm{~mm} \times 180 \mathrm{~mm} \times 1 \mathrm{~mm}$. The electrodes were immersed in the solution at a distance of $20 \mathrm{~mm}$ and were operated in monopolar parallel mode. In order to rotate the solution during the reaction, a magnetic stirrer was used underneath the reactor chamber. A DC power supply was used to provide different current densities.

\section{Experimental unit}

The experiments were performed in a glass batch reactor. The performance of each process alone and the combined EC-PS process in CIP removal was tested. The important parameters in the EC-PS process were $\mathrm{pH}$, current density, initial CIP concentration, contact time and PS concentration. 


\section{Effect of the PS, EC and EC-PS processes}

The solution containing $20 \mathrm{mg} / \mathrm{L}$ of CIP was prepared, and the $\mathrm{pH}$ solution was adjusted to 5 using sulfuric acid $\left(\mathrm{H}_{2} \mathrm{SO}_{4}\right.$, $0.01 \mathrm{M})$ or sodium hydroxide $(\mathrm{NaOH}, 0.1 \mathrm{M})$. The effect of EC, PS and combined EC-PS processes on CIP removal was investigated using the prepared solutions. The reactor was initially operated by EC process with the current density of $1.45 \mathrm{~mA} / \mathrm{cm}^{2}$. In the next step, $1.26 \mathrm{mM}$ of PS was added to the solution to test the effect of the PS process alone. In the final stage, the EC-PS process was excreted at the PS concentration of $1.26 \mathrm{mM}$ and current density of $1.45 \mathrm{~mA} /$ $\mathrm{cm}^{2}$. Sampling was carried out every $10 \mathrm{~min}$ in all processes and filtered with Whatman paper, and finally, the remaining CIP concentration was determined.

\section{Effect of the studied parameters on the EC-PS process}

The effect of important parameters: $\mathrm{pH}$, current density, initial CIP concentration, contact time and PS concentration, was studied in the combined EC-PS process. To evaluate the effect of $\mathrm{pH}$ in the EC-PS process, solutions with CIP concentration of $20 \mathrm{mg} / \mathrm{L}$ were prepared and their $\mathrm{pH}$ adjusted to 3, 5, 7 and 9. Then, other parameters including $\mathrm{pH}$, current density, initial CIP concentration and PS concentration effective in the EC-PS process were fixed. And, so as to investigate the effect of initial PS concentration, all parameters were fixed and PS concentrations were varied $(0.42,0.84$ and $1.26 \mathrm{Mm})$. Also, $0.75,1.45$ and $2.3 \mathrm{~mA} / \mathrm{cm}^{2}$ of current density were applied to study the changes in process performance. Finally, in order to investigate the effect of initial CIP concentration, different concentrations $(10,20$ and $40 \mathrm{mg} / \mathrm{L}$ ) were prepared and the other parameters were fixed. The sampling was performed like the previous section.

\section{Determine of the radical scavengers}

To determine the role of different radicals in the EC-PS process, tert-butanol (TBA) was used as the $\mathrm{OH}$ radical scavenger and methanol was used as both ${ }^{\circ} \mathrm{OH}$ and $\mathrm{so}_{4}^{-\cdot}$ radical scavengers. In EC-PS process, under the optimized conditions, $200 \mathrm{Mm}$ of TBA was added to the solution to investigate the quenching effect of ${ }^{\circ} \mathrm{OH}$. Next, under the optimum conditions, $200 \mathrm{Mm}$ of methanol was added to determine the quenching effect of both $\mathrm{OH}$ and sulfate radicals.

\section{Determine of sludge characterization}

In order to determine the characteristics of the produced sludge in the EC-PS process, the EDS (MIRA3TESCANXMU) and Fourier transform infrared spectroscopy (FTIR) analyses were performed.

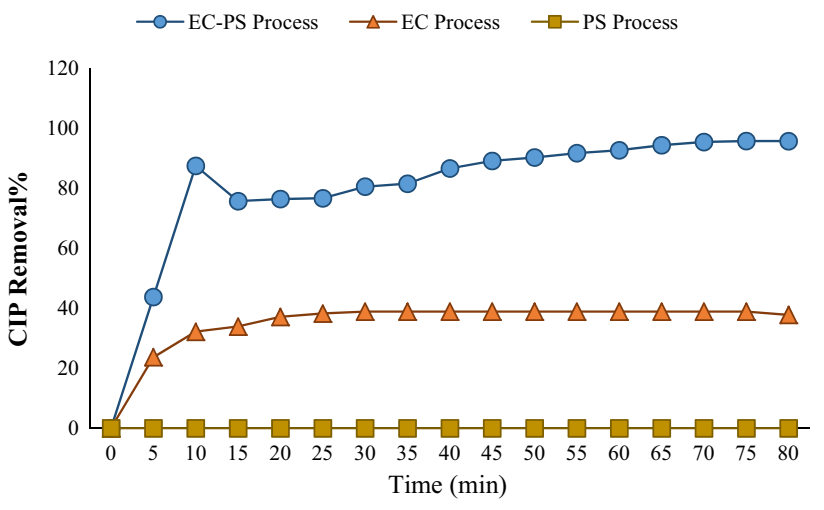

Fig. 2 Effect of PS, EC and EC-PS processes on CIP removal (CIP: $30 \mathrm{mg} / \mathrm{L}$, PS: $1.2 .6 \mathrm{mM}$, current density: $1.45 \mathrm{~mA} / \mathrm{cm}^{2}$ and $\mathrm{pH}: 5$ )

\section{Analysis}

First, the samples first filtered with Whatman paper, and then, the remaining CIP contents were determined using a UV-Vis spectrophotometer (Shimadzu UV-1800, Japan) at $\lambda_{\max }=276 \mathrm{~nm}$. The residual CIP (RE) was calculated by Eq. (3).

$\mathrm{RE}=\frac{\mathrm{CIP}_{0}-\mathrm{CIP}}{\mathrm{CIP}_{0}} \times 100$

where $\mathrm{CIP}_{0}$ and CIP are the initial and final concentrations of CIP as $\mathrm{mg} / \mathrm{L}$, respectively.

\section{Results and discussion}

\section{Effect of EC, PS and EC-PS on CIP removal}

The results of the PS, EC and the EC-PS process for CIP removal from aqueous solutions are shown in Fig. 2. As can be seen, the efficiency of PS in CIP removal was zero. Related studies in which PS alone was used to remove other pollutants have stated similar observations (Liu et al. 2018; Shu et al. 2016). The reason for this phenomenon is that, at very acidic conditions, PS becomes water-oxidized to $\mathrm{H}_{2} \mathrm{O}_{2}$ based on Eqs. 4-6. However, organic pollutants are degraded somewhat due to the fact that hydrogen peroxide is produced at the acidic $\mathrm{pH}$. But, neutral and alkaline conditions similar to the present study, persulfates, convert to $\mathrm{SO}_{4}{ }^{2-}$ and $\mathrm{O}_{2}$ according to Eq. 7; thus, it was not expected that they were efficient in pollutant removal (Bruton and Sedlak 2018; Yang et al. 2018). Another reason why PS alone does not have an effect on the CIP removal is probably the more resistant structure of this antibiotic. Moreover, there is no activator for activating persulfate, which does not affect in CIP removal (Matzek and Carter 2016; Shu et al. 2016; Yang et al. 2018).

$2 \mathrm{~S}_{2} \mathrm{O}_{8}^{2-}+2 \mathrm{H}_{2} \mathrm{O} \rightarrow 4 \mathrm{SO}_{4}^{2-}+\mathrm{O}_{2}+4 \mathrm{H}^{+}$ 
$\mathrm{S}_{2} \mathrm{O}_{8}^{2-}+\mathrm{H}_{2} \mathrm{O} \rightarrow \mathrm{H}_{2} \mathrm{SO}_{5}+\mathrm{SO}_{4}^{2-}$

$\mathrm{H}_{2} \mathrm{SO}_{5}+\mathrm{H}_{2} \mathrm{O} \rightarrow \mathrm{H}_{2} \mathrm{SO}_{4}+\mathrm{H}_{2} \mathrm{O}_{2}$

$2 \mathrm{HSO}_{5}^{-} \rightarrow 2 \mathrm{SO}_{4}^{2-}+\mathrm{O}_{2}+2 \mathrm{H}^{+}$

The removal efficiency of the EC process reached after $30 \mathrm{~min}$, and over the next $50 \mathrm{~min}$ it remained nearly unchanged (Fig. 2). One reason for this phenomenon is the production of hydrogen peroxide via cathodic reduction of oxygen. In the EC process alone, CIP is removed for two reasons: first, direct electrical oxidation on the surface of iron electrodes in the anode and, second, indirect oxidation via hydroxyl radicals formed due to the anodic electrolysis of water (Eq. 8) (Chen et al. 2014; Govindan et al. 2014; Liu et al. 2018; Zhao et al. 2010).

$\mathrm{H}_{2} \mathrm{O} \rightarrow \mathrm{OH}+\mathrm{H}^{+}+\mathrm{e}^{-}$

Based on Fig. 2, the combined EC-PS process was capable of removing effectively CIP from aqueous solutions. Interestingly, $87.5 \%$ of CIP was removed just in $10 \mathrm{~min}$, and then, the removal rate decreased slightly. The efficiency peaked at $96 \%$ within $75 \mathrm{~min}$ and then leveled out. It should be noted that PS has a low oxidation kinetic rate with organic compounds in the absence of an activator and, in turn, oxidizes low amount of pollutants. However, by adding an activator such as electrocoagulation, PS is activated and sulfate radicals are produced in the cathode; of course, PS is regenerated on the anode surface. This leads to the formation of a permanent source of sulfate radicals based on Eqs. 1 and 2 . Thus, the EC-PS process is continuous sources of oxidants, which decomposes contaminants more quickly; it has been reported that $87.5 \%$ of CIP was removed in $10 \mathrm{~min}$ through the EC-PS process (Farhat et al. 2015; Frontistis et al. 2018; Liu et al. 2018).

\section{Calculation of synergistic effect}

In this study, Eq. 9 was used to evaluate the synergistic effects of the EC, PS and combined EC-PS processes.

$\mathrm{SE}=\frac{R_{\mathrm{EC} / \mathrm{PS}}-\left(R_{\mathrm{PS}}+R_{\mathrm{EC}}\right)}{R_{\mathrm{PS}}+R_{\mathrm{EC}}}$

where SE shows the synergistic effect and $R$ is the removal efficiency of each process. The SE value was calculated according to Eq. 9, which was equal to 1.72 for $10 \mathrm{~min}$ for the combined EC-PS process compared to the EC process, because the PS efficiency in CIP removal was zero. As time elapsed, the value for the SE with a slight slope had a decreasing trend and reduced to 1.46 in $75 \mathrm{~min}$ and then fixed. The SE of 1.72 for the combined EC-PS process indicates that this process is 1.72 times more efficient than

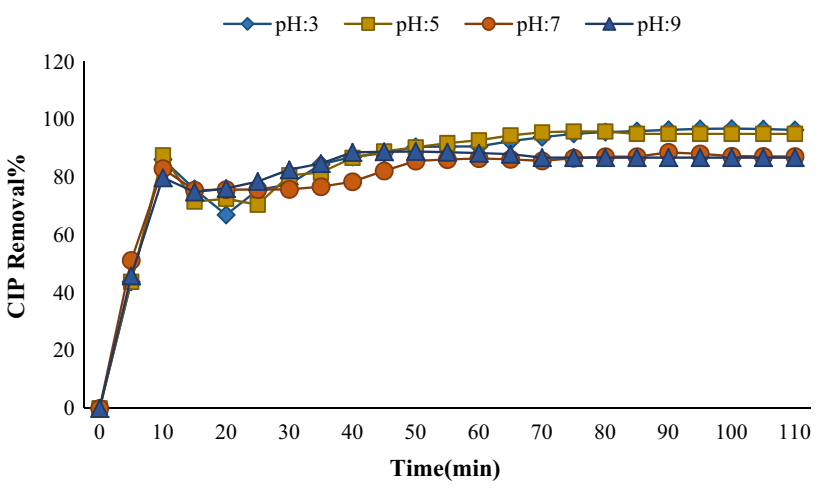

Fig. 3 Effect of $\mathrm{pH}$ changes on CIP removal in EC-PS process (CIP: $30 \mathrm{mg} / \mathrm{L}$, current density: $1.45 \mathrm{~mA} / \mathrm{cm}^{2}$, PS: $1.26 \mathrm{mM}$ and $\mathrm{pH}: 3-9$ )

the EC process in CIP removal. As described in the previous section, the production of sulfate and hydroxyl radicals due to activation of the PS by the electrochemical process is the cause of this increase. The results of this study are consistent with other findings documented in studies in which the EC-PS process was utilized to remove other pollutants (Lin et al. 2013; Liu et al. 2018; Matzek and Carter 2016; Shu et al. 2016).

\section{Effect of pH on EC-PS and pH change over time}

In this part of the study, the effect of initial $\mathrm{pH}$ on the CIP removal from aqueous solutions in the EC-PS process at pH 3, 5, 7 and 9 was studied. Other effective variables were fixed, which included PS $=1.26 \mathrm{mM}, \mathrm{CIP}=30 \mathrm{mg} / \mathrm{L}$ and current density $=1.45 \mathrm{~mA} / \mathrm{cm}^{2}$. It is worth noting that $\mathrm{pH}$ plays a very important role in the EC-PS process. Figure 3 presents the results of using different pHs: 3-9 in the EC-PS process. As can be seen, higher removal efficiencies were attained in acidic pHs of 3 and 5 and have more than neutral and alkaline $\mathrm{pHs}$. The removal efficiency rate at the contact time of 75 min and $\mathrm{pH}$ values of 3, 5, 7 and 9 was 95, 95.85, 87 and $87 \%$, respectively. Therefore, the $\mathrm{pH}$ of 5 was found to be the optimum value. The findings of the related studies have shown that the EC-PS process has a better performance in acidic $\mathrm{pH}$ in pollutant degradation and the removal efficiency improves with decreasing $\mathrm{pH}$. The reason these phenomena is that the sulfate radicals react with water at all pHs, based on Eq. 10, and produce hydroxyl radicals, which are active and primary species in the EC-PS process under alkaline conditions (Eq. 11). On the other hand, in acidic pHs, sulfate radicals that have a higher oxidation potential are dominant ( $\mathrm{Li}$ et al. 2013; Matzek and Carter 2016). Another reason for increasing the efficiency of the EC-PS process with decreasing $\mathrm{pH}$ may be attributed to a decrease in oxygen gas solubility in wastewater, because at low $\mathrm{pH}$ the oxygen gas solubility decreases. And, with decreasing 


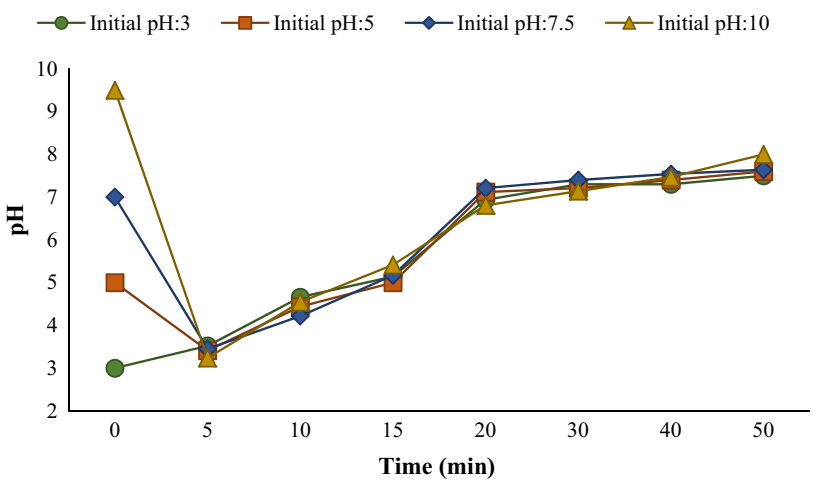

Fig. $4 \mathrm{pH}$ changes at different times in EC-PS process in CIP removal (CIP: $30 \mathrm{mg} / \mathrm{L}$, current density: $1.45 \mathrm{~mA} / \mathrm{cm}^{2}$, PS: $1.26 \mathrm{mM}$ and $\mathrm{pH}: 3-9)$

the dissolved oxygen, the adsorption of persulfate anions in the cathode increases, and, consequently, the formation of sulfate radicals is facilitated because oxygen is competing for the adsorption at the cathode surface with persulfate anions (Chen and Huang 2015; Matzek and Carter 2016).

$\mathrm{SO}_{4}^{-\cdot}+\mathrm{H}_{2} \mathrm{O} \rightarrow \mathrm{SO}_{4}^{2-}+\mathrm{OH}^{-}+\mathrm{H}^{+}$

$\mathrm{SO}_{4}^{-\cdot}+\mathrm{OH}^{-} \rightarrow \mathrm{SO}_{4}^{2-}+\mathrm{OH}^{-}$

\section{pH changes over time on the EC-PS process}

During the EC-PS process, the changes in the initial values of $\mathrm{pH}$ were recorded every $5 \mathrm{~min}$ (Fig. 4). As shown in the figure, after $5 \mathrm{~min}$, all the $\mathrm{pHs}$ tested in the current research declined to 3 . Then, all the values increased further and reached about 7.5 after $30 \mathrm{~min}$ and remained stable until the end of the experiment. The $\mathrm{pH}$ reduction in the solution at the beginning of the reaction is due to the production of $\mathrm{H}^{+}$ based on Eqs. 12-14. Another reason is $\mathrm{OH}^{-}$reduction in the solution based on Eq. (15), which results in a decrease in $\mathrm{pH}$, thereby acidifying the environment (Liu et al. 2018).

$\mathrm{H}_{2} \mathrm{O} \rightarrow \mathrm{HO}^{-}+\mathrm{H}^{+}+\mathrm{e}^{-}$

$2 \mathrm{H}_{2} \mathrm{O}+\mathrm{O}_{2} \rightarrow 4 \mathrm{H}^{+}+4 \mathrm{e}^{-}$

$\mathrm{SO}_{4}^{-\cdot}+\mathrm{H}_{2} \mathrm{O} \rightarrow \mathrm{H}^{+}+\mathrm{SO}_{4}^{2-}+\mathrm{HO}$

$\mathrm{SO}_{4}^{-\cdot}+\mathrm{OH}^{-} \rightarrow \mathrm{SO}_{4}^{2-}+\mathrm{HO}^{\circ}$

In fact, $\mathrm{pH}$ affects iron type, in terms of oxidation states, in the solution, as well as the persulfate reactions with the pollutants. At the initial contact time and acidic $\mathrm{pH}$, the sulfide and hydroxyl radicals are formed based on the above explanations, which cause the CIP oxidation in the EC-PS process; therefore, it should be noted that oxidation plays a major role in this process. The mechanism for the CIP oxidation in the EC-PS process is based on this fact that iron electrodes produce $\mathrm{Fe}^{2+}$ via chemical reactions in the

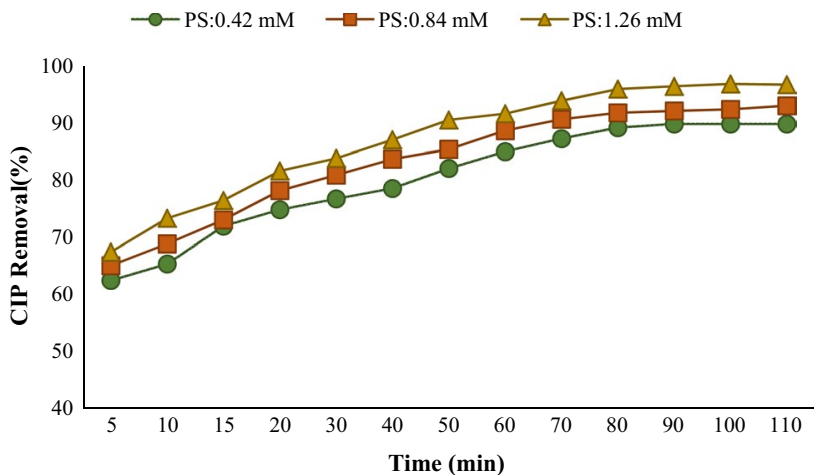

Fig. 5 Effect of PS concentration on CIP removal in EC-PS process (CIP: $30 \mathrm{mg} / \mathrm{L}$, current density: $1.45 \mathrm{~mA} / \mathrm{cm}^{2}, \mathrm{pH}$ : 5 , PS concentration: $0.42-1.26 \mathrm{mM}$ )

anodes (Eq. 16). As a result, the produced $\mathrm{Fe}^{2+}$ activates PS (Eq. 17). On the other hand, PS is regenerated in the cathode (Eq. 18) and it creates a radical sulfate production cycle (Masomboon et al. 2010; Romero et al. 2010; Xu and Li 2010; Zhao et al. 2010).

$\mathrm{Fe}^{0} \rightarrow \mathrm{Fe}^{2+}+\mathrm{e}^{-}$

$\mathrm{S}_{2} \mathrm{O}_{8}^{2-}+\mathrm{M}^{n+} \rightarrow \mathrm{M}^{n+1}+\mathrm{SO}_{4}^{2-}$

$\mathrm{Fe}^{3+}+\mathrm{e}^{-} \rightarrow \mathrm{Fe}^{2+}$

But after the initial time due to increasing $\mathrm{pH}$ in the EC-PS process, $\mathrm{Fe}^{2+}$ solubility decreases and it is converted to $\mathrm{Fe}^{3+}$, which is in the form of colloid. In the present research, the process efficiency decreased after $10 \mathrm{~min}$, because only $\mathrm{Fe}^{2+}$ is able to activate PS. In the next step, $\mathrm{pH}$ started to increase, which is probably due to the hydrogen evolution in the cathode according to Eq. 19 (Mouedhen et al. 2008).

$2 \mathrm{H}_{2} \mathrm{O}+2 \mathrm{e}^{-} \rightarrow \mathrm{H}_{2}+2 \mathrm{OH}^{-}$

As the $\mathrm{pH}$ increases, ferric oxyhydroxides such as $\mathrm{FeOH}^{3+}, \mathrm{Fe}(\mathrm{OH})_{4}^{-}$and $\mathrm{Fe}(\mathrm{OH})_{3}$ were produced. Therefore, the coagulation replaces the oxidation process and plays a major role in the CIP removal, and the efficiency increases again (Masomboon et al. 2010; Romero et al. 2010).

\section{Effect of PS concentration on EC-PS}

Figure 5 shows the results of the PS concentration in the EC-PS process for the CIP removal from aqueous solutions. Other effective parameters in this process were fixed, and different PS concentrations including 0.42, 0.84 and $1.26 \mathrm{mM}$ were tested. An increase in PS concentration enhanced the CIP removal efficiency, but the efficiencies obtained from different concentrations were very close. At the optimum contact time of $75 \mathrm{~min}$, the CIP removal efficiency for concentrations of $0.42,0.84$ and $1.26 \mathrm{mM}$ 


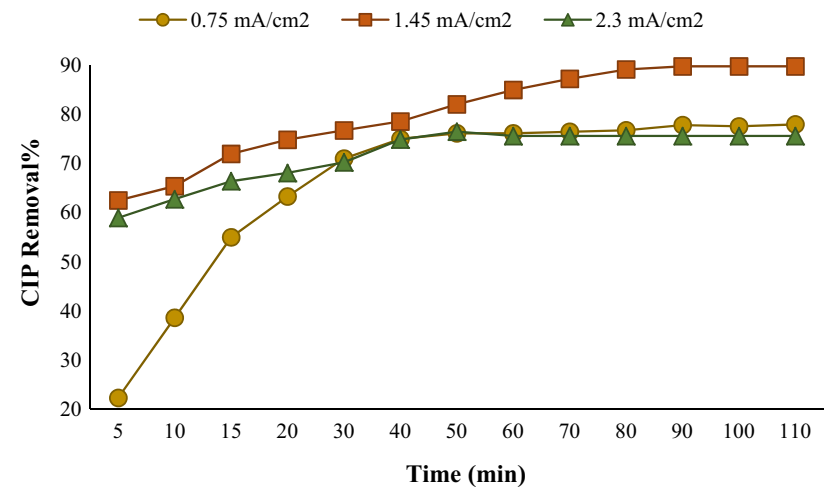

Fig. 6 Effect of current density on CIP removal in EC-PS process (CIP concentration: $30 \mathrm{mg} / \mathrm{L}$, PS concentration: $0.42 \mathrm{mM}$, pH: 5, current density: $0.75,1.45$ and $2.3 \mathrm{~mA} / \mathrm{cm}^{2}$ )

was $89.15,91.75$ and $96 \%$, respectively. The optimum PS concentration should be selected based on economic issues as well as the residual sulfate concentration in the effluent; therefore, the PS concentration of $0.42 \mathrm{mM}$, with a good efficiency about $90 \%$, was selected as the optimum content. Further, many researchers have claimed that increasing PS concentration causes the removal efficiency of pollutants to improve (Ghanbari and Moradi 2017; Wang and Wang 2018; Zhang et al. 2015). This phenomenon may be explained by a significant increase in the number of sulfate radicals, due to an increase in PS concentration, and consequently, the hydroxyl radicals are formed through the EC-PS process; thus, the CIP removal efficiency increases (Chen et al. 2014; Chen and Huang 2015). In similar studies that used the EC-PS process for the removal of various pollutants, PS concentration between 5 and $62.5 \mathrm{mM}$ was reported (Wu et al. 2012; Yuan et al. 2014; Zhang et al. 2014). In comparison with other studies, the PS concentration used in this study was much lower.

\section{Effect of current density on EC-PS}

Figure 6 shows the results of current density in the EC-PS process for the CIP removal from aqueous solutions. And, other parameters effective in this method were fixed. Different current densities of $0.75,1.45$ and $2.3 \mathrm{~mA} / \mathrm{cm}^{2}$ were investigated in this study. As shown in Fig. 6, the CIP removal efficiency increased with increasing current density up to $1.45 \mathrm{~mA} / \mathrm{cm}^{2}$, but with a further increase to $2.3 \mathrm{~mA} / \mathrm{cm}^{2}$, the efficiency decreased. Therefore, the current density, equivalent to $1.45 \mathrm{~mA} / \mathrm{cm}^{2}$, was selected as the optimum value. Current density has always been accepted as an influential variable in electrochemical processes. The bottom line is that at high current densities more sulfate and hydroxyl radical are generated leading to in enhancement in removal efficiency. Also, increasing current density results

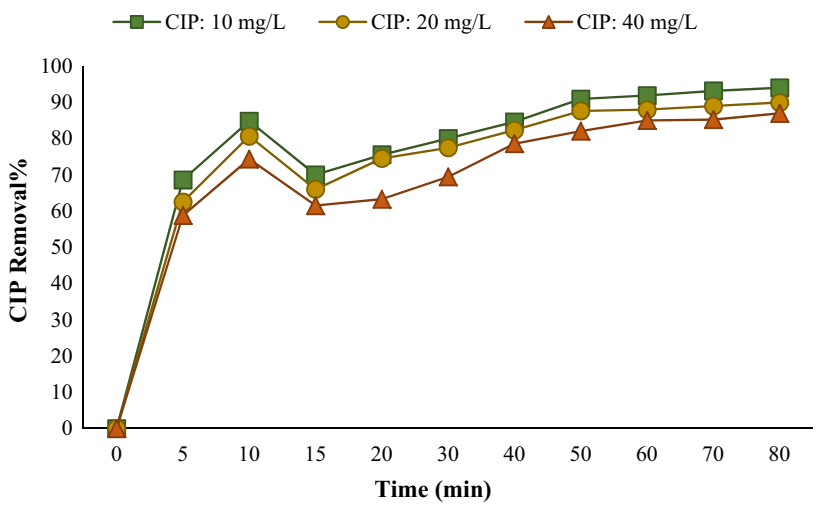

Fig. 7 Effect of current density on CIP removal in EC-PS process (current density: $1.45 \mathrm{~mA} / \mathrm{cm}^{2}$, PS concentration: $0.42 \mathrm{mM}, \mathrm{pH}: 5$, CIP concentration: $10-40 \mathrm{mg} / \mathrm{L}$ )

in the faster generation of sulfate radical, hydroxyl radical and hydrogen peroxide (Chen et al. 2014; Chen and Huang 2015; Frontistis et al. 2018; Liu et al. 2018). However, in this study with a further increase in current density to $2 \mathrm{~mA} /$ $\mathrm{cm}^{2}$, the CIP removal efficiency declined. The cause of this phenomenon may be interpreted by side reactions due to high current density, which leads to the cathodic evolution of hydrogen gas through Eq. 20 (Cai et al. 2014; Liu et al. 2018).

$2 \mathrm{H}^{+}+2 \mathrm{e}^{-} \rightarrow \mathrm{H}_{2}$

\section{Effect of initial CIP concentration on EC-PS}

Figure 7 shows the results of the initial CIP concentration in the EC-PS process for the CIP removal from aqueous solutions. Hence, different initial CIP concentrations: 10, 20 and $40 \mathrm{mg} / \mathrm{L}$, were investigated when other variables were fixed. As can be seen, an increase in CIP concentration in the EC-PS process caused the removal efficiency to go up. The removal efficiency decreased from 94 to $86 \%$ when the CIP concentration increased between 10 and $40 \mathrm{mg} / \mathrm{L}$ at the contact time of $75 \mathrm{~min}$. This decline is because of the fact that the amount of sulfate and hydroxyl radicals produced in the EC-PS process is constant, while the amount of CIP molecules increases; thus, the efficiency decreases. The results of this study accord with the observations of similar studies which used this process for the removal of other pollutants (Cai et al. 2014; Chen et al. 2014; Chen and Huang 2015; Lin et al. 2013; Liu et al. 2018).

\section{Determination of Radical scavengers}

Regarding the presence of both sulfate and hydroxyl radicals in the EC-PS process, a radical scavenger was used to determine the oxidation reaction mechanism and the effect of each of these radicals. In order to determine the role of 


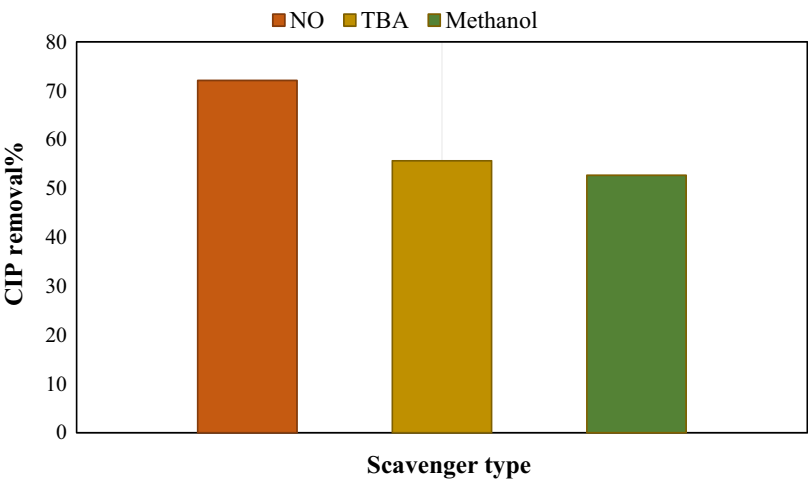

Fig. 8 Effect of radical scavengers on the EC-PS process (current density: $1.45 \mathrm{~mA} / \mathrm{cm}^{2}$, PS concentration: $0.42 \mathrm{mM}, \mathrm{pH}: 5$, CIP: $20 \mathrm{mg} / \mathrm{L}, \mathrm{MA}$ and TBA concentration: $200 \mathrm{mM}$ and time: $20 \mathrm{~min}$ )

different radicals in the EC-PS process, tert-butanol (TBA) was used as ${ }^{\circ} \mathrm{OH}$ radical quencher and methanol (MA) as $\mathrm{OH}$ and sulfate radical quencher. According to Eqs. 21 and 22 , the rate constant of TBA for ${ }^{\circ} \mathrm{OH}$ radicals is 418-900 times greater than the rate constant for $\mathrm{SO}_{4}^{--}$radical. Equations 23 and 24 illustrate that the rate constant of MA for 'OH radical is about 300 times greater than rate that for $\mathrm{SO}_{4}^{-}$. radical (Li et al. 2013; Nasseri et al. 2017).

$$
\begin{aligned}
& \mathrm{t}-\mathrm{BuOH}+\mathrm{OH} \sim 3.8-7.6 \times 10^{8} \mathrm{M}^{-1} \mathrm{~S}^{-1} \\
& \mathrm{t}-\mathrm{BuOH}+\mathrm{SO}_{4}^{-} \sim 4-9.1 \times 10^{5} \mathrm{M}^{-1} \mathrm{~S}^{-1} \\
& \mathrm{MA}+\mathrm{OH} \sim 9.7 \times 10^{8} \mathrm{M}^{-1} \mathrm{~S}^{-1} \\
& \mathrm{MA}+\mathrm{SO}_{4}^{-\cdot} \sim 3.2 \times 10^{6} \mathrm{M}^{-1} \mathrm{~S}^{-1}
\end{aligned}
$$

The results of the radical scavenger studies are shown in Fig. 8; as can be seen, when TBA and MA were added to the EC-PS reactor, the process efficiency decreased from 72 to $55 \%$ and $52 \%$, respectively. Based on the results, a decline in the removal efficiency by adding the TBA and MA radical scavengers is approximately alike. In the EC-PS process, MA could be able to degrade CIP only 3\% more than TBA. The reason for the proximity of the both radical scavengers of TBA and MA is probably associated with the potential role of hydroxyl radical in the anodic formation of sulfate radical, which can disrupt the sulfate radical formation. Therefore, contrary to our imagination, hydroxyl radical plays a major role in the EC-PS process, and sulfate radicals are converted to hydroxyl radical according to Eq. 25. It should be pointed out that the findings obtained in this study are consistent with those reported in the research by Farhat et al. (2015).

$\mathrm{SO}_{4}^{--}+\mathrm{H}_{2} \mathrm{O} \rightarrow \mathrm{SO}_{4}^{2-}+\mathrm{H}^{+}+\mathrm{OH}$

Also, based on the general results of the radical scavenger analysis, the use of MA only reduced about $20 \%$ of the removal efficiency in the EC-PS process (in the absence of a scavengers). The interpretation that can be drawn from these results is that the oxidation process during the initial time plays a major role in the CIP removal, but, over time, the electrocoagulation process becomes the dominant process.

\section{Characterization of chemical structure of the sludge generated by the EC-PS process using the FTIR analysis}

The $\mathrm{KBr}$ disk FTIR spectra of the produced sludge from the EC-PS process at $500-4000 \mathrm{~cm}^{-1}$ are shown in Fig. 9 . According to the FTIR spectrum of the sludge, the wide peak observed at $3373 \mathrm{~cm}^{-1}$ is due to the overlapped $\mathrm{OH}$ and $\mathrm{NH}$ stretching modes with aliphatic $\mathrm{C}-\mathrm{H}, \mathrm{C}-\mathrm{H}$ stretching at $>3000 \mathrm{~cm}^{-1}, \mathrm{C}=\mathrm{O}$ stretching at $1633 \mathrm{~cm}^{-1}$, multiple bands at $1517 \mathrm{~cm}^{-1}$ for $\mathrm{C}=\mathrm{C}$ stretching of aromatic ring, and a sharp peak at $2347 \mathrm{~cm}^{-1}$ is attributed to $-\mathrm{OH}$ acidic functional groups stretching and $\mathrm{C}-\mathrm{N}$ stretching at $1122 \mathrm{~cm}^{-1}$. The absorption peak around $574 \mathrm{~cm}^{-1}$ in FTIR spectra is related to the metal-oxygen bond (Fe-O) (Pavia et al. 2008). The FTIR results show that the produced sludge contained compounds derived from the CIP degradation. Also, the wide peak observed at $3373 \mathrm{~cm}^{-1}$ is due to $\mathrm{OH}$ in combination of $\mathrm{Fe}(\mathrm{OH})_{3}$ produced from the oxidation of the iron electrodes and sludge produced from the EC-PS process.

\section{Characterization of chemical structure of the sludge generated by the EC-PS process using the EDS analysis}

According to the results of the EDS analysis, as shown in Fig. 10, the amounts of carbon, nitrogen, oxygen, fluorine, sodium, sulfur and iron elements in the sludge from the EC-PS process were $3.12,0.67,23.68,0.00,0.06$, 0.88 and 71.59 (wt\%), respectively. This indicates the presence of chemical elements resulted from the destruction of the CIP antibiotic, as well as the presence of hydroxide and metal oxides produced from the EC-PS process in the sludge. High concentrations of iron and oxygen also confirm the formation of the iron hydroxide flocs. The CIP antibiotic also binds to these flocs and separates from the solution. Finally, by analyzing the radical scavenger as well as the FTIR results, it is suggested that the oxidation is dominant in the early stages of the EC-PS process, and the subsequent electrocoagulation plays a major role in the CIP removal. 
Fig. 9 FTIR spectra of the sludge produced from the ECPS process

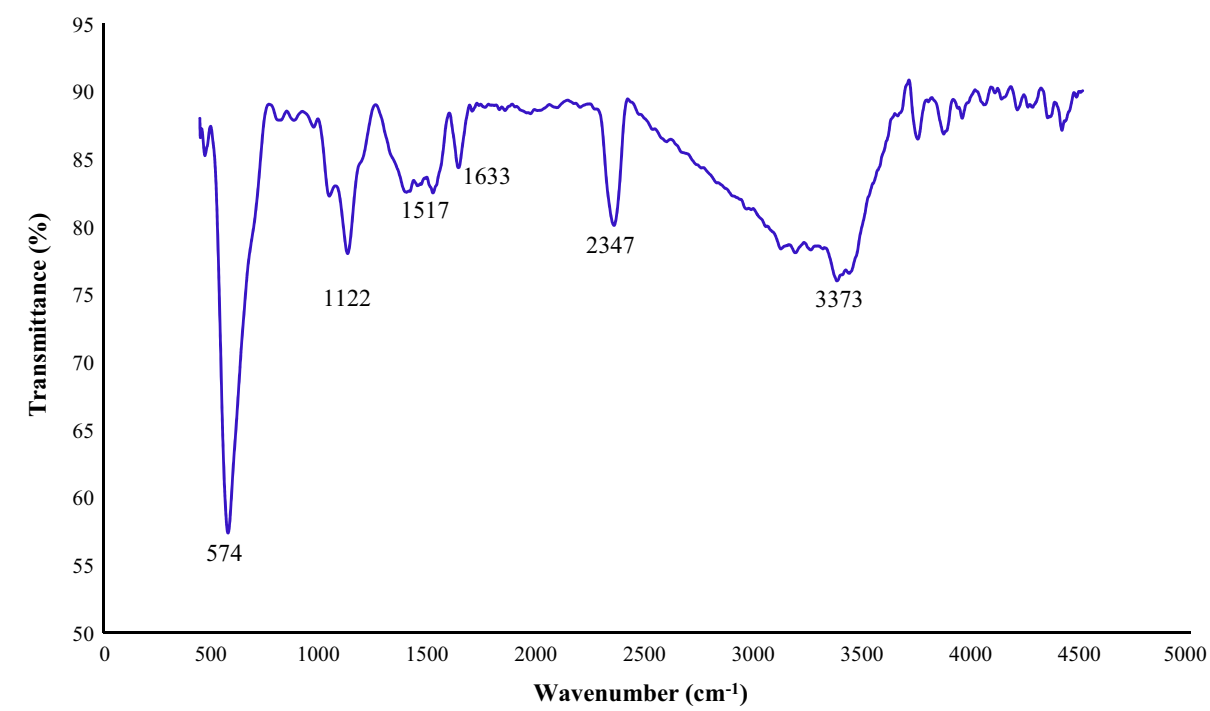

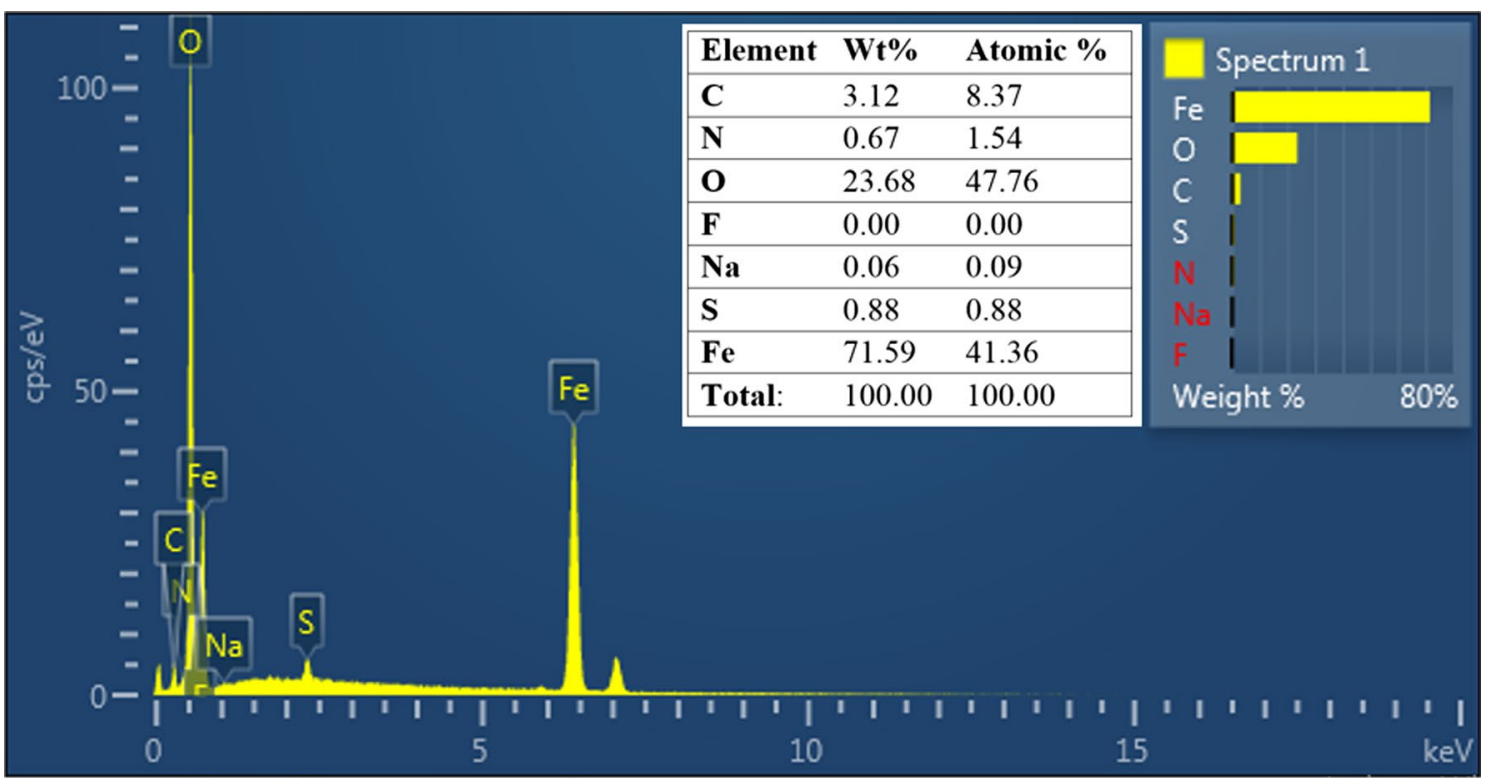

Fig. 10 EDS pattern of the sludge produced from the EC-PS process for CIP removal

\section{Energy consumption calculation}

Industries usually use processes that have high efficiency and are simultaneously cost-effective. Therefore, the calculation of energy consumption in wastewater treatment processes is of great importance. The main operating cost associated with the EC-PS process is the electrical energy consumption during the process. Electric power consumption is calculated according to Eq. 26.

$E=\frac{U I t_{\mathrm{EC}}}{V}$ where $E$ is the electrical energy (Wh), $U$ is the voltage (V), $I$ is the current density (A), $t_{\mathrm{EC}}$ is the time of the process (h) and $V$ is the reactor volume (L). Based on the results obtained in this study, under the optimum conditions, the minimum energy consumption is $0.0045 \mathrm{Wh}$ per mg of CIP removed from the wastewater.

\section{Conclusions}

The widespread use of antibiotics has caused contamination of surface and underground water resources. Antibiotics are not removed by conventional water and wastewater 
treatment methods, and the development of new methods to remove them is indispensable. The purpose of this study was to determine the removal efficiency of CIP by the combined EC-PS process using iron electrodes. In this study, the removal efficiency was similar at different $\mathrm{pHs}$ and the difference in removal efficiency between alkaline and acid $\mathrm{pH}$ was about $10 \%$, with the highest removal efficiency observed in acid $\mathrm{pH}$ of 5. As the PS concentration increased, the CIP removal rate increased, and with increasing initial CIP concentration, the removal efficiency decreased. Increasing the current density up to $45 \mathrm{~mA} / \mathrm{cm}^{2}$ resulted in increased process efficiency, but a further increase reduced the process efficiency. When radical TBA and MA scanners were added to the EC-PS reactor, the process efficiency decreased from $72 \%$ to values of $55 \%$ and $52 \%$, respectively. The EC-PS process using iron electrodes is one of the AOPs that, under the optimum conditions: current density: $1.45 \mathrm{~mA} / \mathrm{cm}^{2}$, PS concentration: $0.42 \mathrm{mM}$, pH: 5, CIP concentration: $10 \mathrm{mg} / \mathrm{L}$ and time: $75 \mathrm{~min}$, could remove more than $94 \%$ of CIP. Finally, the result of radical scavengers as well as FTIR analysis suggests that the oxidation was predominant in the early stages of the EC-PS process, and the subsequent electrocoagulation process played a major role.

Acknowledgements We appreciate the Environmental Health Engineering Research Center of Kerman University of Medical Sciences for providing financial and instrumental support to conduct this work.

\section{Compliance with ethical standards}

Conflict of interest The authors declare that they have no conflict of interests.

Open Access This article is distributed under the terms of the Creative Commons Attribution 4.0 International License (http://creativeco mmons.org/licenses/by/4.0/), which permits unrestricted use, distribution, and reproduction in any medium, provided you give appropriate credit to the original author(s) and the source, provide a link to the Creative Commons license, and indicate if changes were made.

\section{References}

Bruton T, Sedlak D (2018) Treatment of perfluoroalkyl acids by heatactivated persulfate under conditions representative of in situ chemical oxidation. Chemosphere 206:457-464. https://doi. org/10.1016/j.chemosphere.2018.04.128

Cai C, Zhang H, Zhong X, Hou L (2014) Electrochemical enhanced heterogeneous activation of peroxydisulfate by $\mathrm{Fe}-\mathrm{Co} / \mathrm{SBA}-15$ catalyst for the degradation of Orange II in water. Water Res 66:473-485. https://doi.org/10.1016/j.watres.2014.08.039

Chen WS, Huang CP (2015) Mineralization of aniline in aqueous solution by electrochemical activation of persulfate. Chemosphere 125:175-181. https://doi.org/10.1016/j.chemosphere.2014.12.053

Chen W-S, Jhou Y-C, Huang C-P (2014) Mineralization of dinitrotoluenes in industrial wastewater by electro-activated persulfate oxidation. Chem Eng J 252:166-172. https://doi.org/10.1016/j. cej.2014.05.033

Duan W, Wang N, Xiao W, Zhao Y, Zheng Y (2018) Ciprofloxacin adsorption onto different micro-structured tourmaline, halloysite and biotite. J Mol Liq 269:874-881. https://doi.org/10.1016/j. molliq.2018.08.051

Farhat A, Keller J, Tait S, Radjenovic J (2015) Removal of persistent organic contaminants by electrochemically activated sulfate. Environ Sci Technol 49:14326-14333. https://doi.org/10.1021/ acs.est.5b02705

Flaherty CM, Dodson SI (2005) Effects of pharmaceuticals on Daphnia survival, growth, and reproduction. Chemosphere 61:200-207. https://doi.org/10.1016/j.chemosphere.2005.02.016

Frontistis Z, Mantzavinos D, Meriç S (2018) Degradation of antibiotic ampicillin on boron-doped diamond anode using the combined electrochemical oxidation: sodium persulfate process. J Environ Manag 223:878-887. https://doi.org/10.1016/j.jenvm an.2018.06.099

Ghanbari F, Moradi M (2017) Application of peroxymonosulfate and its activation methods for degradation of environmental organic pollutants: review. Chem Eng J 310:41-62. https://doi. org/10.1016/j.cej.2016.10.064

Govindan K, Raja M, Noel M, James EJ (2014) Degradation of pentachlorophenol by hydroxyl radicals and sulfate radicals using electrochemical activation of peroxomonosulfate, peroxodisulfate and hydrogen peroxide. J Hazard Mater 272:42-51. https://doi. org/10.1016/j.jhazmat.2014.02.036

Ji Y, Ferronato C, Salvador A, Yang X, Chovelon J-M (2014) Degradation of ciprofloxacin and sulfamethoxazole by ferrous-activated persulfate: implications for remediation of groundwater contaminated by antibiotics. Sci Total Environ 472:800-808. https://doi. org/10.1016/j.scitotenv.2013.11.008

Lei Y, Zhang H, Wang J, Ai J (2015) Rapid and continuous oxidation of organic contaminants with ascorbic acid and a modified ferric/persulfate system. Chem Eng J 270:73-79. https://doi.org/10.1016/j. cej.2015.02.014

Li B, Li L, Lin K, Zhang W, Lu S, Luo Q (2013) Removal of 1,1,1-trichloroethane from aqueous solution by a sono-activated persulfate process. Ultrason Sonochem 2:855-863. https://doi. org/10.1016/j.ultsonch.2012.11.014

Lin H, Wu J, Zhang H (2013) Degradation of bisphenol A in aqueous solution by a novel electro/ $/ \mathrm{Fe}^{3+} /$ peroxydisulfate process. Sep Purif Technol 117:18-23. https://doi.org/10.1016/j.seppur.2013.04.026

Liu J, Zhong S, Song Y, Wang B, Zhang F (2018) Degradation of tetracycline hydrochloride by electro-activated persulfate oxidation. J Electroanal Chem 809:74-79. https://doi.org/10.1016/j. jelechem.2017.12.033

Masomboon N, Ratanatamskul C, Lu MC (2010) Chemical oxidation of 2,6-dimethylaniline by electrochemically generated Fenton's reagent. J Hazard Mater 176:92-98. https://doi.org/10.1016/j. jhazmat.2009.11.003

Matzek LW, Carter KE (2016) Activated persulfate for organic chemical degradation: a review. Chemosphere 151:178-188. https://doi. org/10.1016/j.chemosphere.2016.02.055

Matzek LW, Carter KE (2017) Sustained persulfate activation using solid iron: kinetics and application to ciprofloxacin degradation. Chem Eng J 307:650-660. https://doi.org/10.1016/j. cej.2016.08.126

Mouedhen G, Feki M, Wery MDP, Ayedi HF (2008) Behavior of aluminum electrodes in electrocoagulation process. J Hazard Mater 150:124-135. https://doi.org/10.1016/j.jhazmat.2007.04.090

Movasaghi Z, Yan B, Niu C (2019) Adsorption of ciprofloxacin from water by pretreated oat hulls: equilibrium, kinetic, and thermodynamic studies. Ind Crops Prod 127:237-250. https://doi. org/10.1016/j.indcrop.2018.10.051 
Nasseri S, Mahvi AH, Seyedsalehi M, Yaghmaeian K, Nabizadeh R, Alimohammadi M, Safari GH (2017) Degradation kinetics of tetracycline in aqueous solutions using peroxydisulfate activated by ultrasound irradiation: effect of radical scavenger and water matrix. J Mol Liq 241:704-714. https://doi.org/10.1016/j.molli q.2017.05.137

Pavia D, Lampman G, Kriz G, Vyvyan J (2008) Introduction to spectroscopy. Cengage Learning, Stamford

Romero A, Santos A, Vicente F, González C (2010) Diuron abatement using activated persulphate: effect of $\mathrm{pH}, \mathrm{Fe}(\mathrm{II})$ and oxidant dosage. Chem Eng J 162:257-265. https://doi.org/10.1016/j. cej.2010.05.044

Shu H-Y, Huang S-W, Tsai M-K (2016) Comparative study of acid blue 113 wastewater degradation and mineralization by UV/persulfate and UV/Oxone processes. Desalination Water Treat 57:2951729530. https://doi.org/10.1080/19443994.2016.1172031

Tran TV et al (2019) MIL-53 (Fe)-directed synthesis of hierarchically mesoporous carbon and its utilization for ciprofloxacin antibiotic remediation. J Environ Chem Eng 7:102881. https://doi. org/10.1016/j.jece.2019.102881

Wang J, Wang S (2018) Activation of persulfate (PS) and peroxymonosulfate (PMS) and application for the degradation of emerging contaminants. Chem Eng J 334:1502-1517. https://doi. org/10.1016/j.cej.2017.11.059

Wu J, Zhang H, Qiu J (2012) Degradation of acid Orange 7 in aqueous solution by a novel electro/ $\mathrm{Fe}^{2+} /$ peroxydisulfate process. $\mathrm{J}$ Hazard Mater 215-216:138-145. https://doi.org/10.1016/j.jhazm at.2012.02.047

Wu S et al (2013) Adsorption of ciprofloxacin onto biocomposite fibers of graphene oxide/calcium alginate. Chem Eng J 230:389-395. https://doi.org/10.1016/j.cej.2013.06.072

Xiaodong D, Yongqing Z, Imtyaz H, Shaobin H, Weilin H (2017) Insight into reactive oxygen species in persulfate activation with copper oxide: activated persulfate and trace radicals. Chem Eng J 313:1023-1032. https://doi.org/10.1016/j.cej.2016.10.138

Xu X-R, Li X-Z (2010) Degradation of azo dye Orange G in aqueous solutions by persulfate with ferrous ion. Sep Purif Technol 72:105-111. https://doi.org/10.1016/j.seppur.2010.01.012

Yang Y, Banerjee G, Brudvig GW, Kim J-H, Pignatello JJ (2018) Oxidation of organic compounds in water by unactivated peroxymonosulfate. Environ Sci Technol 52:5911-5919. https://doi. org/10.1021/acs.est.8b00735

Yuan S, Liao P, Alshawabkeh AN (2014) Electrolytic manipulation of persulfate reactivity by iron electrodes for trichloroethylene degradation in groundwater. Environ Sci Technol 48:656-663. https://doi.org/10.1021/es404535q

Zhang H, Wang Z, Liu C, Guo Y, Shan N, Meng C, Sun L (2014) Removal of COD from landfill leachate by an electro/ $/ \mathrm{Fe}^{2+} /$ peroxydisulfate process. Chem Eng J 250:76-82. https://doi. org/10.1016/j.cej.2014.03.114

Zhang M, Chen X, Zhou H, Murugananthan M, Zhang Y (2015) Degradation of p-nitrophenol by heat and metal ions co-activated persulfate. Chem Eng J 264:39-47. https://doi.org/10.1016/j. cej.2014.11.060

Zhao H-Z, Sun Y, Xu L-N, Ni J-R (2010) Removal of acid Orange 7 in simulated wastewater using a three-dimensional electrode reactor: removal mechanisms and dye degradation pathway. Chemosphere 78:46-51. https://doi.org/10.1016/j.chemosphere.2009.10.034

Publisher's Note Springer Nature remains neutral with regard to jurisdictional claims in published maps and institutional affiliations. 